\title{
EXPERIÊNCIAS E ESTRATÉGIAS NO ENSINO DE HISTÓRIA SOBRE GÊNERO E SEXUALIDADE NA EDUCAÇÃO BÁSICA EM TRIUNFO/CANDEIAS DO JAMARI- RO
}

\author{
Lauri Miranda Silva \\ Programa de Pós-Graduação em História da Universidade Federal do Rio Grande do Sul \\ (PPGH/UFRGS), Brasil \\ E-mail: laurifenty@gmail.com \\ ORCID: https://orcid.org/0000-0001-9487-9615
}

Data de recebimento: $13 / 02 / 2020$

Data de aprovação: 25/03/2020

DOI: https://doi.org/10.30612/frh.v22i39.12569

\begin{abstract}
Resumo: O presente artigo tem por objetivo relatar as experiências e estratégias no ensino de História com as temáticas de gênero e sexualidade vivenciadas durante a execução do trabalho intitulado Projeto de Gênero e Sexualidade na Escola (PGSE) desenvolvido com os alun@s do $9^{\circ}$ ano do Ensino Fundamental e $3^{\circ}$ ano do EJA (Educação de Jovens e Adultos) no período de 2016 a 2018. O projeto ocorreu na Escola Estadual de Ensino Fundamental e Médio Albino Buttner que se localiza numa zona considerada de difícil provimento na região Norte do Brasil, no Distrito de Triunfo/Candeias do Jamari em Rondônia. Os objetivos estabelecidos foram: ensinar, conscientizar, sensibilizar e discutir com@s alun@s e a comunidade escolar acerca das diversas formas de discriminações e de violências a partir do bullying praticado no ambiente escolar, debatendo, por meio de recursos didáticos, estratégias de aprendizagens (músicas, dinâmicas, filmes e exposições) que contribuem para a ampliação do conhecimento acerca da homotransfobia, machismo, sexismo e feminicídio, respeitando a pluralidade de pensamento, a cidadania e a sua importância para compreensão das diferenças de tod@s@s alun@s e o apreço à tolerância.
\end{abstract}

Palavras-chave: Ensino de história. Diversidade sexual. Relações de gênero.

\section{PRACTICES AND STRATEGIES OF THE TEACHING OF HISTORY ON SEXUAL DIVERSITY AND GENDER RELATIONS IN PRIMARY AND LOWER SECONDARY EDUCATION IN TRIUNFO/CANDEIAS DO JAMARI, RONDONIA}

Abstract: The objective of this article is to describe the practices and strategies in the teaching of history on the themes of gender and sexuality which were experienced during the application of a project called Project of Gender Sexuality at School (Projeto de Gênero Sexualidade na Escola - PGSE), developed with ninth grade elementary school students and third-year students from EJA (the youth and adult education program) from 2016 to 2018. This project was carried out at the State Elementary and High School Albino Buttner which is located in a hard-to-reach area in the North of Brazil, in the district of Triunfo/Candeias do Jamari, Rondonia. Its objectives were: teaching, educating, raising awareness and discussing with the students and the community about the many forms of discrimination and violence which emerged from the bullying practiced in the school setting, debating, by means of pedagogical resources, learning strategies (songs, dynamics, movies and exhibitions) which 
contribute to a broader knowledge of homotransphobia, chauvinism, sexism and feminicide, respecting plurality of thought, citizenship and its role in the understanding of difference and appreciation of tolerance.

Keywords: Teaching of history, Sexual diversity, Gender relations.

\section{EXPERIENCIAS Y ESTRATEGIAS EN LA HISTORIA DE LA ENSEÑANZA SOBRE EL GÉNERO Y LA SEXUALIDAD EN LA EDUCACIÓN BÁSICA EN TRIUNFO / CANDEIAS DO JAMARI-RO}

Resumen: El propósito de este artículo es informar sobre las experiencias y estrategias en la enseñanza de la historia con los temas de género y sexualidad experimentados durante la ejecución del trabajo titulado Proyecto para la sexualidad de género en la escuela (PGSE) desarrollado con estudiantes del noveno grado de la escuela primaria. y 3er año de EJA (Educación de Jóvenes y Adultos) en el período de 2016 a 2018. El proyecto tuvo lugar en la Escuela Primaria y Secundaria Estatal Albino Buttner, que se encuentra en un área considerada difícil de proporcionar en el norte de Brasil, en el Distrito de Triunfo / Candeias do Jamari en Rondônia. Los objetivos establecidos fueron: enseñar, sensibilizar, sensibilizar y debatir con los estudiantes y la comunidad escolar sobre las diversas formas de discriminación y violencia basadas en el acoso practicado en el entorno escolar, debatiendo, a través de recursos didácticos, estrategias de aprendizaje ( música, dinámica, películas y exposiciones) que contribuyen a la expansión del conocimiento sobre la homotransfobia, el sexismo, el sexismo y el feminicidio, respetando la pluralidad del pensamiento, la ciudadanía y su importancia para comprender las diferencias de todos los estudiantes seo apreciación de la tolerancia.

Palabras clave: Enseñanza de historia. Diversidad sexual. Relaciones de genero.

\section{Introdução}

O presente artigo tem por objetivo relatar as experiências e estratégias no ensino de História com as temáticas de gênero e sexualidade vivenciadas durante a execução do trabalho intitulado Projeto de Gênero e Sexualidade na Escola (PGSE) desenvolvido com os alun@s do $9^{\circ}$ ano do Ensino Fundamental e $3^{\circ}$ ano da EJA (Educação de Jovens e Adultos) no período de 2016 a 2018. O projeto ocorreu na Escola Estadual de Ensino Fundamental e Médio Albino Buttner que se localiza numa zona considerada de dificil provimento na região Norte do Brasil, no Distrito de Triunfo/Candeias do Jamari em Rondônia. Esse trabalho se desdobra em quatro partes: na primeira parte teço alguns apontamentos a cerca da escola como um multi-espaço de sociabilidade para o enfrentamento de diversas formas de opressões interseccionadas; na segunda parte faço alguns apontamentos sobre o papel d@s professor@s 
no ensino de história e a necessidade de autoatualização para as discussões dos temas de diversidade sexual e relações de gênero numa perspectiva humanística e não-heteronormativa; na terceira parte relato as minhas experiências e estratégias no ensino de história para corroborar na luta contra a homostransfobia e a violência de gênero a partir dos direitos humanos; e por último faço as considerações do trabalho desenvolvido em Rondônia.

\section{A escola e o enfrentamento contra as opressões}

Compreendo que a escola é um multi-espaço democrático, cultural e social. É para ser um lugar de trocas de conhecimentos e experiências, mas também de sociabilidades e de (in) formações contra as diversas formas de opressões e intolerâncias, garantindo o pleno exercício da cidadania de tod@s alun@s, independente de gênero, raça, classe, orientação sexual, etnia ou religião numa perspectiva dos direitos humanos.

Nesse sentido, a escola é um lugar de construção, desconstrução e reconstrução dos saberes (RIOS; MENDES, 2018), onde@s alun@s possam apreender não somente os conteúdos pragmáticos das disciplinas em sala de aula, mas também receber formações para aprender a lidar com as diferenças no ambiente escolar e na sociedade. A escola não deve ser um espaço predominantemente da heteronormatividade e, muito menos, púlpito para que pessoas propaguem seus preconceitos através de princípios religiosos fundamentalistas. A escola é laica e precisa ser o lugar da pluralidade de pensamentos e ideias.

Nesse sentido, ressalto a importância da luta dos movimentos sociais de mulheres e/ou feministas, LGBTIQ+ e negr@s que, historicamente, contribuem para essas discussões numa perspectiva dos direitos humanos e sociais, os quais, em muitos casos, colaboram para a inclusão de estudos específicos nos currículos. De acordo com Paiva (2018), mesmo com as discussões do Plano Nacional de Educação e os debates regionais com suas especificidades locais: Lamentavelmente, vivemos em uma época marcada pela construção social dos papéis pautados nas relações de poder estabelecidas de maneira dicotômica: homem/mulher, brancos/negros, hetero/homo, ciência/ideologia (PAIVA, 2018, p. 13).

Estamos vivendo retrocessos nas políticas sociais no campo educacional no país. Políticos conservadores e fundamentalistas inventaram um mecanismo denominado de "Ideologia de Gênero" cujo objetivo é atacar e perseguir principalmente professor@s, discriminando mulheres e LGBTIQ+, ferindo os princípios do Estado de Direito e a liberdade de catédra. O ambiente escolar também é um local onde a reprodução do machismo, sexismo, 
misoginia, racismo e homotransfobia são existentes entre@s alun@s, professor@s e demais funcionários que perpetuam essas opressões e violências de maneira física, verbal e simbólica, causando transtornos psicológicos para mulheres e LGBTIQ+. Dessa forma, contribuem para a evasão e exclusão de alun@s vítimas de bullyng, principalmente, de alun@s trans.

$\mathrm{Na}$ escola, infelizmente é comum ouvir de certos alun@s frases como: “aquele é um viadinho e tem que apanhar", "olha a piriguete", "pode bater, é puta”, "mariquinha”, "vira homem", "é viado", "vixe, é sapatão" e outras diversas formas discriminatórias e vexatórias que colaboram para a estigmatização e violência. ${ }^{1}$ A escola peca quando em seu projeto político pedagógico e/ ou no currículo não há estratégias para combater essas discriminações, marginalizando alun@s que estão fora do padrão hegemônico.

Diante disso, é importante ressaltar que temos mecanismos legais (Constituição Federal, PCN'S, BNCC, LDB/9394, Declaração dos Direitos Humanos, Diretrizes Curriculares Nacionais da Educação Básica e a Lei Maria da Penha) que concedem suporte para a implementação de novas práticas pedagógicas no que tange às questões de equidade de gênero, educação sexual, pluralidade cultural, identidade de gênero, gravidez na adolescência e infecções sexualmente transmissíveis. Sobre essas questões, cito apenas os itens 1 e 9 das competências gerais da educação básica da Base Nacional Curricular Comum (BNCC):

Valorizar e utilizar os conhecimentos historicamente construídos sobre o mundo físico, social, cultural e digital para entender e explicar a realidade, continuar aprendendo e colaborar para a construção de uma sociedade justa, democrática e inclusiva.

Exercitar a empatia, o diálogo, a resolução de conflitos e a cooperação, fazendo-se respeitar e promovendo o respeito ao outro e aos direitos humanos, com acolhimento e valorização da diversidade de indivíduos e de grupos sociais, seus saberes, identidades, culturas e potencialidades, sem preconceitos de qualquer natureza (BRASIL, 2017, p. 9).

Nessa concepção, a escola precisa se resguardar com esses aparatos para fazer desse espaço pedagógico não só um local de conhecimento, mas de respeito, acolhimento, solidariedade e inclusão das diferenças, criando um ambiente democrático e livre de opressões.

\section{O papel d@ docente de história no tocante às relações de gênero e diversidade sexual no ambiente escolar}

1 Já presenciei e fui alvo enquanto aluna trans de alguns desses termos preconceituosos, e também os ouvi nas escolas onde trabalhei. 
Concordo com Batista (2018) quando ele fala que tratar sobre gênero e sexualidade numa perspectiva dos direitos humanos e políticas públicas nos cursos de graduação (em especial nos de licenciatura) e nas escolas de ensino básico se tornou uma missão necessária de professor@s devido ao aumento da homotransfobia e da violência contra mulheres no Brasil.

O Brasil está entre os cincos piores países para as mulheres viverem. O debate em torno das diversas formas de opressões consolidadas contra as mulheres é recente e as políticas públicas que existem ainda são ineficazes. Mesmo com a Lei Maria da Penha (2006), a mudança na lei de estupro (2009), a lei do feminicídio (2015) e a mais atual lei de importunação sexual (2018), a onda de violência contra as mulheres só aumenta. Diariamente, vemos relatos de agressões e feminicídios nas redes sociais e na mídia (VIOLÊNCIA..., 2018). O Brasil é o país que mais mata LGBTIQ+ no mundo. Em março desse ano, foi lançada a plataforma "Violência contra pessoas LGBTIQ+ nos contextos eleitoral e póseleitoral". Os números são alarmantes e não deixam dúvidas sobre o aumento da violência durante e após as eleições de $2018 .^{2}$

Nesse sentido, qual o papel d@s professor@s de história na abordagem de gênero e sexualidade em sala no ambiente escolar? O que el@s têm feito no tocante à homotransfobia, machismo e sexismo em suas aulas? Para Batista (2018), paralelamente às políticas da educação que definem o currículo:

[...] está a ação docente, que executa um currículo real ou interativo, correspondente ao que é efetivamente realizado na sala. $\mathrm{O}$ modo como esse currículo é colocado em prática depende das experiências acumuladas pelo/a professor/a ao longo da sua trajetória formativa (BATISTA, 2018, p. 118).

Há muitos problemas na formação e falta de experiências de professor@s de história que começam na graduação. Sabemos que, na história, emergiram novos objetos e novas abordagens como, por exemplo: a história de mulheres e a história da sexualidade. Foi a partir, sobretudo, da Nova História na década de 70, beneficiada da ampliação da

2 Na plataforma "Violência contra as Mulheres em Dados" estão os principais dados, relatório completo, reportagens, entrevistas e a base de dados aberta. Foram aplicados 400 questionários em São Paulo, Rio de Janeiro e Salvador em janeiro de 2019. Para mais detalhes, ver: Violência contra LGBTs + nos contextos eleitoral e pós-eleitoral. Disponível em: http://violencialgbt.com.br/dados/190321_relatorio_LGBT_V1.pdf ou http://violencialgbt.com.br/?fbclid=IwAR0MK1IskIB1Zdpcjs6vG1O5pp-7g7ZusBXY15ptydlyPfAnUfOyq_sK60. Acesso em: 15 maio 2019. 
Antropologia Histórica, que entrou em pauta o debate do papel da família e da sexualidade e também a história das mulheres.

Assim, iniciou-se um novo fazer historiográfico subversivo que surgiu para se contrapor ao paradigma tradicional que se pensava e escrevia sobre a política ligada especificamente ao Estado (uma história vista de cima, cujas prioridades em seus estudos eram as realizações dos heróis e estadistas) deixando à margem a história de mulheres, da sexualidade e outros temas considerados marginais na história por parte de historiadores tradicionais (BURKE, 1992).

Esse novo campo de estudo passou a se preocupar com toda atividade humana (limpeza, sexualidade, leitura, cotidiano, gestos e etc.), reconfigurando e impactando a escrita da história. Objetos que pareciam naturais, como corpo e sexualidade, também passaram a ser historicizados, ou seja, vistos em suas permanências e transformações. Saliento que historiador@s em nossa contemporâneidade têm se preocupad@s com esses temas considerados ainda tabus no Brasil. O crescimento de eventos, seminários e congressos sobre mulheres e LGBTIQ+ na história, nos mostra essa visibilidade.

Contudo, parece que uma grande parcela de professor@s no Brasil não receberam uma boa formação para lidar com as questões de gênero e sexualidade na disciplina de história, o que ocasiona problemas na prática pedagógica em sala de aula. Até mesmo os cursos de formações continuadas, quando são oferecidas para@s professor@s que estão nas escolas, não concedem visibilidades para esses temas tão importantes e cruciais para atualização dess@s profissionais.

Sei de todo o descaso com a educação pública, dos problemas que @s profissionais dessa área passam, mas temos também que nos ater ao nosso ofício no ambiente escolar, então, o que ensinar? Como lidar com temas de gênero e sexualidade em sala de aula? Como trabalhar com pluralidade de alun@s? O nosso papel é contribuir substantivamente para a constituição dos vínculos de identidades e promover o desenvolvimento reflexivo da cidadania de noss@s alun@s com escolhas pedagógicas inclusivas. Quando se trata, principalmente, de atitudes preconceituosas e discriminatórias em sala de aula, o nosso papel está no lecionar e no educar para que alun@s possam aprender os conteúdos programáticos da disciplina e também o respeito às diversidades sexuais, religiosas, étnicas e etc. através de uma pedagogia revolucionária de resistência, uma pedagogia engajada. (HOOKS, 2017).

Muit@s professor@s despreparad@s, machistas e homotransfóbic@s têm contribuído para as lógicas perversas de diversas formas de opressões no ambiente escolar, eu mesma já 
Experiências e estratégias no ensino de História sobre gênero e sexualidade na Educação Básica em Triunfo/Candeias do Jamari - RO - Lauri Miranda Silva

presenciei colegas de profissão fazendo chacotas e discriminando alun@s considerad@s fora do padrão heteronormativo. É claro que eu não me calei diante dos fatos porque se calar diante de situações como essas é ser conivente com tais atos. Nas redes sociais, já vi comentários de professores de história com preconceitos à alun@s trans no uso do banheiro feminino, ou seja, há sim a presença de professor@s de história conservadores nas escolas, deturpando o nosso ofício de ensinar para a cidadania e sensibilizar para a boa convivência d@s alun@s na sociedade.

Portanto, é necessário repensar o papel d@s professor@s no ensino de história, promover ações pedagógicas e mecanismos voltadas às temáticas de gênero e sexualidade. $\mathrm{O}$ nosso trabalho se relaciona com os direitos humanos e não podemos de forma alguma corroborar com o sexismo, homotransfobia, machismo e racismo na escola. Assim, é importante destacar que@profess@r de história precisa sair do marasmo, precisa modificar seu pensamento e sua prática, como nos diz Freire:

Faz parte igualmente do pensar certo a rejeição mais decidida a qualquer forma de discriminação. A prática preconceituosa de raça, de classe, de gênero ofende a substantividade do ser humano e nega radicalmente a democracia. Quão longe dela nos achamos quando vivemos a impunidade dos que matam meninos nas ruas, dos que assassinam camponeses que lutam por seus direitos, dos que discriminam os negros, dos que inferiorizam as mulheres (FREIRE, 1996, p. 39-40).

Junkeira (2009) analisou a pesquisa "Perfil dos Professores Brasileiros" realizada pela Unesco, em 2002. Nela foram entrevistad@s 5 mil professor@s da rede pública e privada. O estudo revelou, entre outros assuntos, que, para 59,7\% del@s, é inadmissível que uma pessoa tenha relações homoafetivas e que $21,2 \%$ deles tampouco gostariam de ter vizinhos LGBTQI+. O autor ainda cita outra pesquisa pela mesma instituição, em 13 capitais brasileiras e no Distrito Federal, que forneceram certa compreensão do alcance da homotransfobia no ambiente escolar. Detectou-se que o percentual de professores/as que declaram não saber como abordar os temas relativos à homossexualidade em sala de aula vai de 30,5\% em Belém a 47,9\% em Vitória. Os que acreditam ser a homossexualidade uma doença são cerca de $12 \%$ de professores/as em Belém, Recife e Salvador, entre 14 e 17\% em Brasília, Maceió, Porto Alegre, Rio de Janeiro e Goiânia e mais de 20\% em Manaus e Fortaleza (JUNKEIRA, 2009, p. 17)

Seguindo os ensinamentos de Bell Hooks (2017), quando encontramos salas de aulas com alun@s diversos em termos étnicos, religiosos e/ou sexuais, @ profess@r precisa se 
preparar ou estar preparad@, buscar (in) formações e se capacitar para trabalhar com esses sujeitos de forma inclusiva, (re) pensando estratégias alternativas para sua prática pedagógica no ensino. Conforme a autora, "os professores devem ter o compromisso ativo com um proceso de autoatualização que promova seu próprio bem-estar. Só assim poderão ensinar de modo a fortalecer e capacitar" (HOOKS, 2017, p. 28). Ainda de acordo com ela:

Os professores que abraçam o desafio de autoatualização serão mais capazes de criar práticas pedagógicas que envolvam os alunos, proporcionando-lhes maneiras de saber que aumentem sua capacidade de viver profunda e plenamente (HOOKS, 2017, p. 36).

Os temas sobre gênero e diversidade sexual ainda são invizibilizados no ensino de história, a presença deles nos livros didáticos é vaga e superficial, incumbindo @s professor@s a buscarem outros mecanismos ou ferramentas didáticas para dar suporte ao aprendizado d@s alun@s e sanar dúvidas e/ou curiosidades que irão aparecer em sala de aula. O papel d@ profess@r no ensino de história está no enfrentamento em sala de aula à violência de gênero, à homotransfobia e a outras diversas formas de opressões; está no respeito a cada voz individual d@s alun@s independente de identidade de gênero, raça, orientação sexual, classe ou religiosidade. Nesse sentido, no tópico abaixo mostro, a partir da minha experiência enquanto professora na educação básica, algumas estratégias interdisciplinares que deram suporte para a minha prática pedagógica.

\section{Educando para o respeito a diversidade sexual e a valorização de mulheres e LGBTIQ+ O local e a criação do projeto}

O Distrito de Triunfo se localiza na região Norte do Brasil, no município de Candeias do Jamari, Estado de Rondônia. O povoamento se iniciou na década de 1990, com a abertura da linha 631, iniciada por uma construtora de nome Triunfo. O distrito tem aproximadamente quatro mil habitantes. Nessa região, considerada como de difícil acesso, há três escolas: Albino Buttner, Jonatas Coelho Neiva e Leonora Atanásio. Ganham destaque manifestações culturais como: comemoração do dia 7 de setembro, Rodeio, Festa de São João, Corrida da Argolinha e a Cavalgada. A presença da prática religiosa é visível em Triunfo com igrejas de várias denominações como católica, protestante, pentencostal e neopentencostal (há mais de 26 Igrejas). A economia da localidade é baseada na agropecuária, serrarias, carvoarias e comércio. 
O Projeto de gênero e sexualidade foi desenvolvido na Escola Estadual de Ensino Fundamental e Médio Albino Buttner, onde ministrei as disciplinas de História Geral e História de Rondônia durante quase seis anos. A execução do projeto se deu nos anos de 2016 a 2018, no segundo semestre de cada ano, com as turmas de $9^{\circ}$ Ano do ensino fundamental (matutino e vespertino) e $3^{\circ}$ Ano da Educação de Jovens e Adultos (noturno). Os objetivos eram os de: ensinar, conscientizar, sensibilizar e discutir com@s alun@s e a comunidade escolar as questões de discriminação e violência a partir do bullying na escola, homotransfobia, machismo, sexismo e feminicídio, respeitando a pluralidade de pensamento de cada sujeito.

Toda a efetivação do projeto esteve sob o respaldo do meu plano de curso da disciplina História Geral ${ }^{3}$ através do eixo temático "Cidadania e cultura no mundo contemporâneo: relações de poder, nações e cotidiano" sob a perspectiva de alguns dos descritores de habilidades e competências:

- Analisar historicamente os processos de exclusão/inclusão social promovidas pelas sociedades, considerando o respeito aos direitos humanos e à diversidade;

- Utilizar procedimentos históricos e de outras ciências auxiliares na construção do conhecimento histórico escolar;

- Participar de tarefas grupais que convidem ao intercâmbio de opiniões, à consideração de diferentes pontos de vista;

- Conhecer e compreender os diversos aspectos das transformações ocorridas na sociedade;

- Compreender que somos agentes do processo histórico sendo capazes de intervir e modificar o meio.

A construção do projeto se deu a partir de três temas: a era da contestação, ditadura militar no Brasil e democratização do Brasil, conteúdos pragmáticos do livro didático História doc. $9^{\circ}$ Ano (VAINFAS et al., 2015). Os mesmos conteúdos coincidiram com os assuntos trabalhados no $3^{\circ}$ Ano da EJA (ressalto que essa modalidade de ensino é carente de livros didáticos específicos para@s professor@s trabalharem suas disciplinas nas escolas de Rondônia, dessa forma, criamos estratégias de conteúdos, usando livros antigos e novos de turmas do ensino fundamental e médio).

Então criei o projeto, anexando-o ao plano de aula e ao plano de curso para trabalhar com@s alun@s no 3o bimestre dos anos 2016, 2017 e 2018. Tais documentos foram

3 Os Planos de Cursos das escolas estaduais em Rondônia são feitos no início do ano letivo. 
entregues à equipe pedagógica da escola que ficou sensibilizad@ com o tema proposto e que também prestigiou o resultado final, juntamente com a comunidade escolar.

Mesmo se tratando de um tema considerado ainda tabu na sociedade brasileira e apesar do fato da localidade ter um número elevado de alun@s católic@s e protestantes, essas características não foram obstáculos para que o projeto fosse um sucesso e não teve retaliação por parte da comunidade escolar.

\section{Metodologia/ estratégia didática}

Duas semanas depois de eu ter trabalhado os temas das aulas sobre a era da contestação, ditadura militar no Brasil e democratização do Brasil, e também seguindo o cronograma de aula, para não acontecer cobranças da equipe pedagógica, iniciei o projeto com uma dinâmica sobre as questões das diferenças. Distribuí para@s alun@s folhas de papel sufit ou A4 em branco. Na dinâmica, el@s tinham o objetivo de desenhar um sujeito como el@s quisessem. Mencionei algumas coordenadas pedindo que el@s fizessem em sequência: cabeça, cabelo, olhos, boca, nariz, até formar o desenho por completo ou incompleto, deixando-@s à vontade caso desejassem colocar adereços (chapéu, laços, brincos, bolsas e etc). No final, teriam que fazer a troca dos desenhos com @s colegas de sala. Escolhi alguns e algum@s alun@s para que explanassem sobre os desenhos em mãos, comentando as características em comum e/ou diferentes dos seus desenhos para@s d@s colegas. O resultado dessa dinâmica mostra a diversidade de sujeitos construídos por el@s. Nessa dinâmica, temos que deixar@s alun@s se expressarem e, no final,@ profess@r faz considerações sobre a atividade.

Foi a partir dessa dinâmica que iniciei o debate sobre gênero e sexualidade, incluindo aulas teóricas com uma linguagem de fácil compreensão; textos sobre cidadania e o respeito às diferenças; movimento LGBTIQ+ e suas conquistas; orientação sexual, identidade de gênero, práticas sexuais, homotransfobia, violência contra mulheres, mercado de trabalho, educação e saúde; e atividade de pesquisa sobre gênero e sexualidade.

Em um outro momento, trabalhei com músicas brasilerias que reproduzem machismo, violência contra mulher e homofobia, tais como: "Baile de Favela" - MC João, "Loira burra" - Gabriel, O Pensador, "Amiga da minha mulher" - Seu Jorge, "Um tapinha não dói" Bonde do Tigrão, "Mulher não manda em homem" - Grupo Vou pro Sereno, "Maria sapatão" 
Experiências e estratégias no ensino de História sobre gênero e sexualidade na Educação Básica em Triunfo/Candeias do Jamari - RO - Lauri Miranda Silva

e "Cabeleira do Zezé" - Chacrinha, "Vale Tudo" - Tim Maia, e "Rock das aranhas" - Raul Seixas.

Nessa etapa do projeto,@s alun@s se divertiram dando risadas das letras e até mesmo dançando.Eu@s deixei se manifestarem durante a amostra das músicas. Quando terminou, fizemos diversas reflexões sobre as letras de forma crítica, pois@s alun@s não tinham a visão de que músicas machistas e homofóbicas contribuem para a discriminação e violência contra LGBTIQ+ e mulheres.

Nessa etapa, realizei um cine-debate, passando alguns filmes para@s alun@s relacionarem com os conteúdos ministrado no projeto, como: "Milk, A voz da igualdade", "Orações para Bobby" e "O casamento de Gorete". Além disso, exibi alguns documentários sobre identidade de gênero, famílias X LGBTIQ+ e depoimentos de mulheres e LGBTIQ+ vítimas de violências. Esse trabalho aúdio-visual foi comovente. Em sala de aula, muit@s@s alun@s ficaram pensativ@s e outr@s emocionad@s com o que assistiram, sensibilizad@s com os temas abordados.

A penúltima etapa das atividades ocorreu com a produção de textos a partir do que foi trabalhado no projeto. Solicitei que@s alun@s fizessem uma redação sobre Violência e crimes contra mulheres, LGBTIQ+ e outras "minorias" com base em algumas perguntas semi-abertas para conduzi-1@s na criação textual. Selecionei alguns trechos da redação resguardando e respeitando o anonimato de cada alun@ e mantendo a escrita del@s.. As perguntas foram: você conhece alguém que já sofreu algum tipo de violência devido à orientação sexual ou identidade de gênero? Qual sua opinião sobre a diversidade sexual? Qual sua opinião sobre o projeto de gênero e sexualidade na escola?

Nessa etapa, foi possível perceber a sensibilização e a aceitação do tema por parte de um@d@s alun@s quando el@menciona que: “É importante falar sobre isso no ambiente escolar para mostrar para os alunos, que os gays, transexuais, bissexuais e outros tipos de pessoas, devem ser aceit@s do jeito que elas são e gostam, é o que faz ela se sentir bem.” (Alun@1).

Sobre o entendimento através do debate da diversidade de identidades em sala de aula, temos análises como:

Cada um de nós temos sua própria identidade, somos diferentes um do outro, não devemos julgar ninguém porque não sabemos o que nos espera, esse

4 São textos d@s alun@s do 9ªno na faixa etária de 14 a 17 anos. 
projeto retrata muito de cada um de nós, então a gente tem que parar e pensar em tudo que falamos, pensamos ou fazemos (Alun@ 2 ).

Então temos que deixar as pessoas ser o que quiserem e respeitá-las pelo caráter e pelas qualidades que cada um tem. Existe pessoas de todo jeito, branco, preto, pardo, homem, mulher, gay, lésbica, entre outras personalidades, isso não importa e sim a pessoas ser feliz e saber respeitar as pessoas (Alun@4).

É importante descidimos sobre esses assuntos para tambem entendermos que as pessoas que sofrem preconceitos por essas coisas passam na escola, em casa e em todos os lugares, temos que entender que cada um de nós temos uma identidade, e temos que nós aceitar do jeito que somos, sem se importar para que os outros vão dizer (Alun@ 5).

@s alun@s, portanto, conseguiram compreender que somos diferentes no tocante à identidade de gênero, étnica e racial, e que o respeito é crucial para convivermos com essas diferenças no ambiente escolar e na comunidade. Esse entendimento por parte d@s alun@s do "diferente" e das diversidades é de extrema importância no processo de formação educacional. Promovendo o respeito às pessoas que estão fora do padrão heternormativo e aos direitos humanos, valorizando a diversidade de indivíduos e de grupos sociais, sem preconceitos ou discriminação de qualquer natureza, ess@s alun@s estão contribuindo para um aprendizado transformador, libertário e emancipatório em sala de aula.

Durante a explanação sobre as políticas públicas para LGBTIQ+ e mulheres, levei para a sala de aula alguns textos sobre o assunto para que@s alun@s tivessem o conhecimento das conquistas e dos desafios dos movimentos sociais na luta contra o machismo e a homotransfobia. Ao mostrar os dados de violências que ocorrem no Brasil, uma aluna me questionou se já havia uma lei específica que crimininaliza a violência contra homossexuais. Então expliquei que existiam alguns projetos na Câmara dos Deputados, mas que, devido aos políticos conservadores e tradicionalistas, tinham sidos engavetados. Porém, o Movimento LGBTIQ+ continuava na luta contra a homotransfobia. Em seus textos, @s alun@s reconheceram as diversas formas de opressões e de violência. Além disso, perceberam a importância de se conscientizar e discutir esses temas no ambiente escolar:

Eu sei que agressão não se resolve com violência, não deveria existir em nosso mundo, todos nós somos iguais, o que muda é a nossa sexualidade, não devemos se importar se é homem ou mulher, não importa, nós devemos respeitar, todos reagem de uma forma quando vê um homem beijando outro homem, ou uma mulher beijando outra mulher, nós devemos mostrar para o mundo inteiro uma coisa que eles não vê direito o amor ao próximo... devemos falar para toda a escola, que a violência, preconceito e agressão não 
chega a lugar nenhum, devemos mostrar que a violência da cadeia, que o preconceito é a pior coisa (Alun@3).

No Brasil muitas pessoas não aceitam homossexuais, e por isso xingam e batem até mesmo com palavras. Na realidade as pessoas que são violentadas têm mesmo que denunciar(Alun@11).

A importância disso ser discutido no ambiente escolar é que ajuda acabar com os preconceitos, ajuda que os transexuais e os outros sejam aceitos no mundo todo e que possam ter uma vida normal, possam se casar com quem eles querer(Alun@7).

Um dos objetivos do meu trabalho foi justamente tornar o tema democrático e sensibilizar@s alun@s através de suas falas e de suas escritas conduzindo-@s a um projeto sócio-educacional para um país livre de opressões e violências e uma escola mais solidária e inclusiva.

A maioria d@s alun@s não conhecia pessoas que foram vítimas de homotransfobia, mas, durante as aulas e as pesquisas realizadas por el@s, ficaram cientes do que ocorre no país. Abaixo está relatado um caso de violência que foi citado em um dos textos elaborados pel@s alun@s:

Conheço, tenho um amigo que mora em Machadinho, um dia ele se reuniu com uns colegas dele, nem todos que estavam no grupo sabiam que ele era guey, descobriram na hora, teve dois rapazes que não gostaram de saber que tinha um guey no grupo, beberam tanto, brigaram com esse meu colega e acabaram esfaqueando ele, ele ficou internado, mas não morreu (Alun@10).

A homotransfobia acontece no grupo familiar e de amigos, no trabalho e em outros lugares públicos, onde os LGBTIQ+, em sua maioria, acabam sem acolhimento. O Brasil está no topo do ranking de países que registram mais agressões contra essa população. É preciso que as escolas e outras insituições promovam os mais diversos tipos de atividades e projetos sócio-educacionais, discutindo a inclusão social, o preconceito, o reconhecimento desse segmento historicamente invisibilizado e estigmatizado no país, bem como a luta contra a violência de gênero para que@s alun@s possam colaborar na luta contra as injustiças sociais. Esse é o caso d@ alun@ que desconhece alguém que tenha sofrido algum tipo de violência desse tipo, mas que, em seu texto, explana de maneira solidária que apoia e lutará pela causa:

Eu não conheço ninguém que sofreu algum tipo de violência, mas sei a fama do bullyng no Brasil e sei que pessoas sofrem muito com isso e a minha opinião eu não acho nem uma graça esse jeito de preconceito com quem só quer ser feliz e eu apoio e se eu puder ajudar eu ajudarei com maior prazer (Alun@ 8). 
Desde quando nascemos, somos ensinad@s a agir de acordo com o nosso sexo biológico e/ou de acordo com a prática religiosa de cada sujeito. O sexo dos indivíduos é, assim, culturalmente determinado antes de nascerem. Crescemos ouvindo que "menino tem que usar roupas na cor azul, para a menina rosa é a cor destinada", "menino não chora", "menina brinca de boneca" e outras expressões que continuam sendo ensinadas. Essas questões foram trabalhadas em sala de aula sobre as relações de gênero, orientação sexual e identidade de gênero, no entanto, reconhecendo e valorizando as expressões e vozes de cada alun@, independente de religião. Encontrei em alguns textos entregues por el@s as seguintes opiniões no que tange à homossexualidade :

É normal, pela minha forma de criação da educação dos meus pais e pela minha religião que eu acredito eu acho errado, mais não tenho nada contra, posso ter amigos ou até meus futuros filhos gays ou lésbicas que eu não vou ter nenhum tipo de preconceito (Alun@9).

Eu Alun@11 sou cristão, para mim isto é pecado, Deus não aceita, mas cada um pode ser da maneira que quiser com Deus ou sem Deus, mas se uma pessoa homossexual chega para mim, querendo ser meu amigo, eu não vou desprezar(Alun@11).

As pessoas religosas não aceitam os gays porque não estão na Biblía, outros diz que é pecado, enfim são humanos também e tem direito igual ao do homem e da mulher... por isso na nossa escola estamos desenvolvendo esse projeto(Alun@14).

Percebe-se claramente nesses trechos a questão que envolve a religião e a homossexualidade.@s alun@s, através de seus princípios religiosos, expõem suas opiniões baseadas na Bíblia e nos ensinamentos tradicionais no seio familiar. O mais importante, em suas falas, é o respeito e a inclusão de homossexuais em seus vínculos sociais.

Como produto final do projeto, depois de todas as aulas téoricas, dinâmica, trabalhos com músicas e filmes e a produção de textos, escolhi uma das turmas e sugeri que@s alun@s compartilhassem e trocassem os conhecimentos adquiridos no desenvolvimento do projeto com@s demais colegas, professor@s, equipe gestora e toda a comunidade escolar.

@ s alun@s do $9^{\circ}$ do período vespertino realizaram uma mini-feira cultural e se dividiram em grupos, pesquisaram dados sobre a homotransfobia e violência contra mulheres, fizeram cartazes explicando os conceito de gênero, identidade de gênero, orientação sexual, e pesquisaram imagens de pessoas famosas internacionais e nacionais que assumiram ao público as suas orientações sexuais. Cada turma se dirigiu ao pátio da escola acompanhada 
d@ professo@r para prestigiar o trabalho d@s alun@s. Eu mediei as dúvidas e algumas curiosidades d@s alun@s e até mesmod@s professor@s, principalmente sobre identidade de gênero. Algumas turmas me questionaram do porquê eu não ter trabalhado o projeto com el@s também, eu expliquei que fazia parte dos contéudos específicos das tumas do $9^{\circ}$ ano e $3^{\circ}$ ano, mas que opotunidades não iriam faltar para abordar o tema em sala de aula.

A mini-feira cultural de gênero e sexualidade ficou exposta à comunidade escolar durante dois dias, até mesmo para que@s alun@s do período noturno, em especial os $3^{\circ}$ anos do ensino médio e $3^{\circ}$ EJA, para que pudessem contemplar a "finalização" do trabalho desenvolvido. Ressalto que a maioria d@s alun@s que realizou o evento são das chamadas linhas, que moram em sítios ou fazendas.Cinco@alun@s se comprometeram de estar à noite para explanar o resultado do projeto.

\section{Considerações não-finais}

Desde 2004 vivenciamos um processo de desqualificação da escola pública no Brasil, com políticos fundamentalistas e conservadores através do Projeto Escola Sem Partido, perseguindo professor@s de diversas maneiras, censurando e auto-censurando o trabalho de educador@s que estão realizando debates no ambiente escolar sobre as questões de gênero e sexualidade, ferindo nossa liberdade de cátedra. De acordo com os adeptos do Projeto, a escola estaria ensinando, entre outros temas "perigosos", a Ideologia de Gênero. De maneira mais direta, estaríamos ensinando@s alun@s a serem LGBTIQ+. Sabemos que isso é uma inverdade propagada por parte desses políticos visando manter as aparências e o status quo: um sistema de dominação masculino hegemônico, classista, sexista, racista e homotransfóbico.

A nossa liberdade de cátedra é garantida por lei, nós, professor@s, temos direitos e deveres de ensinar, aprender e compartilhar saberes com a comunidade escolar, através do pluralismo de ideias e de concepções pedagógicas, trabalhando numa perspectiva humanística de solidariedade humana, sempre pensando na formação de cada alun@, preparando-@ para exercer a sua cidadania, qualificando-@ para a vida, com respeito à liberdade e tolerância à singularidade, independente de gênero, identidade de gênero, orientação sexual, classe, raça, religião e etnia.@s professor@s precisam ter a compreensão de seus direitos e deveres, necessitam fazer uma autoatualização em sua formação, afinal, somos intelectuais, somos produtores do conhecimento, principalmente quando se trata de trabalhar temas como 
diversidade sexual e relações de gênero com crianças e jovens na escola, possibilitando a construção de uma boa conduta profissional e consciente no trato dessas temáticas. Precisamos, também, estabelecer uma relação de confiança com a comunidade escolar, principalmente,com@s alun@s.

É nesse sentido que o meu Projeto de Gênero e Sexualidade se inseriu, criando perspectivas de resistências, de construção coletiva e democrática a partir do ensino de história na educação básica, contribuindo para o ensino de história e a formação da cidadania d@s alun@s em Rondônia, incorporando novos instrumentos para uma boa prática pedagógica, como dinâmicas, músicas, filmes e a feira cultural da diversidade sexual e de gênero, buscando incluir @s alun@s no processo de aprender-saber, conscientizando e sensibilizando para as questões dos direitos humanos, numa perspectiva da educação engajada e transformadora. Visibilizando também as lutas dos movimentos de mulheres e de LGBTIQ+ na história contra as opressões do sistema cisheteropatriarcal.

\section{Referências}

BATISTA, Ricardo dos Santos. Provocações para ampliar os estudos sobre gênero, sexualidade e o ensino de história. In: RIOS, Pedro Paulo Souza; MENDES, Alane Martins (org.). Educação, gênero e diversidade sexual: fabricação das diferenças no espaço escolar. Curitiba: CRV, 2018.

BRASIL. Ministério da Educação. Lei no 9.394, de 20 de dezembro de 1996. Estabelece as diretrizes e bases da educação nacional. Diário Oficial da União, Brasília, 23 de dezembro de 1996. Disponível em: http://www.planalto.gov.br/ccivil_03/leis/L9394.htm. Acesso em: 23 ago. 2019.

BRASIL. Ministério da Educação; Secretaria de Educação Básica; Secretaria de Educação Continuada, Alfabetização, Diversidade e Inclusão; Secretaria de Educação Profissional e Tecnológica. Conselho Nacional de Educação; Câmara de Educação Básica. Diretrizes Curriculares Nacionais da Educação Básica. Brasília: MEC; SEB; DICEI, 2013.

BRASIL. Ministério da Educação. Governo Federal. Base Nacional Curricular Comum: BNCC-Educação é a base. 2017. Disponível em: http://basenacionalcomum.mec.gov.br/images/BNCC_EI_EF_110518_versaofinal_site.pdf. Acesso em: 09 set. 2019.

BURKE, Peter (org.). A escrita da História: novas perspectivas. São Paulo: Unesp, 1992. FREIRE, Paulo. Pedagogia da autonomia: saberes necessários à prática educativa. São Paulo: Paz e Terra, 1996.

JUNKEIRA, Rogério Diniz (org.). Diversidade sexual na Educação: problematizações sobre a homofobia nas escolas. Brasília: Ministério da Educação, Secretaria de Educação Continuada, Alfabetização e Diversidade, UNESCO, 2009. 
HOOKS, Bell. Ensinando a transgredir: a educação como prática da liberdade. Trad. Marcelo Brandão Cipolla. São Paulo: Martins Fontes, 2017.

LASSO, Pablo. Antropologia cultural e homossexualidade: variantes do comportamento sexual, culturalmente aprovadas. In: VIDAL, M; MARTOS, J. M. F; GAFO, J; HIGUERA; G; RUIZ, G. (org.). Homossexualidade: ciência e consciência. São Paulo: Edições Loyola, 1985.

PAIVA, Carla Conceição da Silva. Prefácio. In: RIOS, Pedro Paulo Souza; MENDES, Alane Martins (org.). Educação, gênero e diversidade sexual: fabricação das diferenças no espaço escolar. Curitiba: CRV, 2018.

RIOS, Pedro Paulo Souza; MENDES, Alane Martins. Educação, gênero e diversidade sexual: fabricação das diferenças no espaço escolar. Curitiba: CRV, 2018.

VAINFAS, Ronaldo; FARIA, Sheila de Castro; FERREIRA, Jorge; CALAINHO, Daniela Buono (org.). Historia doc. $9^{\circ}$ ano. São Paulo: Saraiva, 2015.

VIOLÊNCIA contra as Mulheres em Dados: plataforma reúne pesquisas, fontes e sínteses sobre o problema no Brasil. In: VIOLÊNCIA contra as Mulheres em Dados. [São Paulo: Instituto Patrícia Galvão, 2018]. Disponível em: https://dossies.agenciapatriciagalvao.org.br/violencia-em-dados/sobre-esta-plataforma/. Acesso em: 12 set. 2019. 